\title{
Are the standard parameters of cervical spine alignment and range of motion related to age, sex, and cervical disc degeneration?
}

\author{
Baoge Liu, MD, ${ }^{1}$ Bingxuan Wu, MD, ${ }^{1}$ Tom Van Hoof, PhD, ${ }^{2}$ Jean-Pierre Kalala Okito, PhD, MD, ${ }^{3}$ \\ Zhenyu Liu, MD, ${ }^{1}$ and Zheng Zeng, MD1
}

'Department of Orthopaedics, Beijing Tian Tan Hospital, Capital Medical University, Beijing, China; ${ }^{2}$ Department of Basic Medical Sciences; and '3epartment of Neurosurgery, Ghent University Hospital, Ghent University, Ghent, Belgium

\begin{abstract}
OBJECT The aims of this study were 1) to establish the standard parameters of alignment and total and segmental range of motion (ROM) of the cervical spine in the asymptomatic population, and 2) to identify factors that influence cervical ROM and alignment.
\end{abstract}

METHODS The authors measured 636 standard cervical lateral, flexion, and extension plain radiographs of 212 asymptomatic volunteers. The relationship between cervical alignment and total ROM was assessed with simple linear regression. Multivariate linear regression was used to determine the effect of the influential factors on cervical alignment and total and segmental ROM.

RESULTS The mean value for C2-7 cervical alignment was $21.40^{\circ} \pm 12.15^{\circ}$, and the mean value for total $\mathrm{ROM}$ was $63.59^{\circ} \pm 15.37^{\circ}$. Sex was a significant factor in cervical alignment, total ROM, and segmental ROM for C2-3 and C5-6 $(p<0.05)$. Age had a significant negative association with both the total ROM and all of the segmental ROM measurements $(p<0.05)$. Cervical disc degeneration at the level of interest had a significant negative association with $C 4-5$, C5-6, and C6-7 ROM ( $p<0.05)$.

CONCLUSIONS Cervical alignment in female subjects was $2.47^{\circ}$ lower than that in male subjects. Total ROM was $3.86^{\circ}$ greater in female than in male subjects and decreased $6.46^{\circ}$ for each decade of aging. Segmental ROM decreased $1.28^{\circ}$ for each decade of aging and $2.26^{\circ}$ for each category increase in disc degeneration at the level of interest.

http://thejns.org/doi/abs/10.3171/2015.1.SPINE14489

KEY WORDS cervical alignment; cervical range of motion; cervical spine; disc degeneration; influential factors; degenerative

Pring ERVICAL degenerative disc disease is being increasingly observed in older populations. Signs of cervical spine degeneration may appear as abnormal cervical alignment and range of motion (ROM) ${ }^{16,19}$ which are usually diagnosed on plain radiographs. ${ }^{3-6,8,10}$ Previous studies have determined the normal parameters for cervical alignment and ROM and some of the factors influencing cervical ROM using plain radiographs ${ }^{20,22,26}$ However, the effect of degeneration on segmental ROM, especially in asymptomatic individuals, remains unclear.
Okada et al. ${ }^{18}$ assessed disc degeneration in asymptomatic subjects using magnetic resonance imaging and found that degenerative disc changes were apparent in $17 \%$ of male subjects and $12 \%$ of female subjects in the 2 nd decade of life, and that $14 \%$ of male subjects and $11 \%$ of female subjects in their 6th decade showed no apparent degenerative disc changes. They also found that disc degeneration had no correlation with the occurrence of future clinical symptoms. ${ }^{19}$ Cervical disc degeneration can be found in asymptomatic individuals, and the effect of

ABBREVIATIONS ICC = intraclass correlation coefficient; ROM = range of motion.

SUBMITTED May 14, 2014. ACCEPTED January 9, 2015.

INCLUDE WHEN CITING Published online June 19, 2015; DOI: 10.3171/2015.1.SPINE14489.

DISCLOSURE This work was supported by the National Natural Science Foundation of China (no. 81171764). 
degeneration on cervical segmental ROM should be elucidated with respect to factors other than age. Several cadaveric and symptomatic studies ${ }^{1,11,22}$ have been performed to investigate the effect of disc degeneration on segmental ROM. However, there are cervical ROM changes associated with the development of neck pain.7,12 A previous study by our team has shown the relation between the instantaneous center of rotation and cervical disc degeneration in asymptomatic subjects. ${ }^{14}$ In this study, we performed radiographic studies of the cervical spines of 212 asymptomatic volunteers and demonstrated the effect of disc degeneration on segmental ROM, based on a scoring system for cervical disc degeneration, ${ }^{25}$ which can be used to assess the degree of cervical disc degeneration for 3 independent variables.

By analyzing the plain radiographs of asymptomatic subjects, we attempted to establish standard parameters for cervical alignment and total and segmental ROM in different sex and age groups and to establish cervical segmental ROM measurements in groups with different grades of disc degeneration. We also explored the association between these parameters and age, sex, and cervical disc degeneration.

\section{Methods}

We enrolled 300 asymptomatic volunteers with an age range of 20-79 years. The exclusion criteria included severe neck or shoulder pain, neurological symptoms, a history of cervical trauma or surgery, and pregnancy. We excluded 88 volunteers; 6 of these volunteers were excluded from the study because of congenital or acquired synostosis and 82 because the inferior endplate of C-7 was not adequately visible on plain radiographs. The remaining 212 asymptomatic volunteers were included in the study. This study was approved by the Human Investigations Committee to Protect Human Subjects in Research of Beijing Tiantan Hospital affiliated with Capital Medical University, and all volunteers gave informed consent.

Standard neutral lateral radiographs (Eastman Kodak) were obtained with subjects maintaining their natural posture. They were instructed to keep their right shoulder close to the cabinet; the distance between the x-ray tube and the detector was $150 \mathrm{~cm}$. The focus of the beam was directed horizontally to the C-4 vertebral body. Before exposure, subjects were asked to close their eyes, flex and extend their "head" (craniocervical junction) twice, and then open their eyes when they assumed that they were looking straight ahead at a comfortable resting position. Full flexion and full extension radiographs of the cervical spine were obtained by asking the subjects to try their best to maintain positions of maximal flexion and extension.

All of the images were imported into Mimics 15.0 software (Materialise) and then measured and blindly assessed for degree of cervical disc degeneration by 2 junior and 1 senior spine surgeon 3 times at 1-week intervals. Blinding was accomplished by removing identifying information on the radiographs and randomly assigning them to each examiner.

Cervical alignment and ROM were measured using the 2-line Cobb angle method and superimposing the $2 \mathrm{im}$ ages for image registration (Fig. 1).,15,17,21 We measured cervical alignment, total ROM (flexion and extension), and segmental ROM (flexion and extension). The angle of cervical lordosis was set as a positive value and kyphosis as a negative value.

The degree of degeneration at each cervical level was assessed on the neutral-position lateral radiograph using the scoring system for cervical disc degeneration presented by Walraevens et al. ${ }^{25}$ This scoring system was shown to be reliable and objective in a previous study, with excellent intrarater agreement (intraclass correlation coefficient $[$ ICC $]=0.86$, range $0.75-0.93$ ) and interrater agreement (ICC $=0.78$, range $0.64-0.88$ ). The system classifies the severity of disc degeneration from no degeneration to severe degeneration (score range 0-9) on the basis of 3 variables: height loss, anterior osteophytes, and endplate sclerosis. Height loss is defined as the difference between the height (measured at the center of the disc) of the disc at the level being assessed and the height of a disc without any sign of degeneration at an adjacent level, scored from 0 to 4 points. The length of the anterior osteophytes is measured with respect to the anteroposterior diameter of the corresponding vertebral body, which is measured at the middle of the vertebral body, scored from 0 to 3 points. The endplate sclerosis is scored from 0 to 2 points. Based on the sum of the scores for the 3 variables, the extent of cervical disc degeneration was classified as no degeneration ( 0 point), mild degeneration (1-3 points), moderate degeneration (4-6 points), or severe degeneration (7-9 points). This scoring system has been widely used in large cross-sectional studies. ${ }^{2,13,23,24}$

SPSS 13.0 (IBM SPSS Inc.) was used for statistical analysis. Values are presented as mean \pm SD. Interrater and intrarater agreement were analyzed, and simple linear regression was used to quantify the relationship between cervical alignment and ROM. Multivariate linear regression was used to analyze cervical alignment, total ROM, and segmental ROM. Regression coefficients and $p$ values are presented.

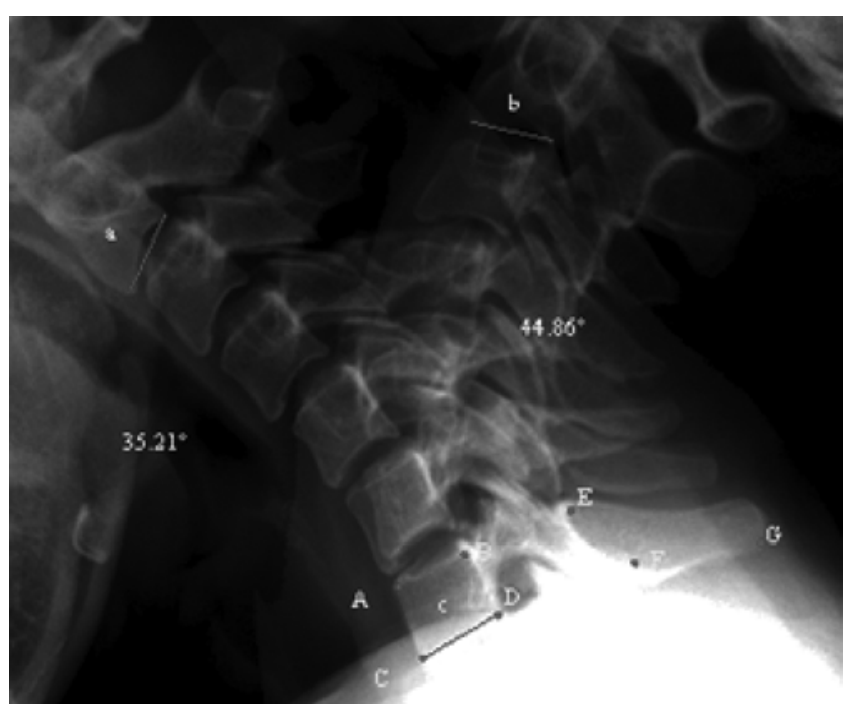

FIG. 1. Radiographic image showing the measurement of total cervical $\mathrm{ROM}$. The C-7 vertebrae on 2 lateral flexion-extension plain radiographs were superimposed for image registration and to measure the values of C2-7 flexion ROM, extension ROM, and total ROM. 
TABLE 1. C2-7 alignment and flexion, extension, and total ROM

\begin{tabular}{cccccc}
\hline & & \multicolumn{5}{c}{ Mean \pm SD $\left(^{\circ}\right)$} \\
\cline { 3 - 6 } Group & No. of Subjects & Alignment & ROM & Flexion ROM & Extension ROM \\
\hline Total & 212 & $21.40 \pm 12.15$ & $63.59 \pm 15.37$ & $-25.34 \pm 9.80$ & $38.24 \pm 11.31$ \\
\hline Sex & & & & $-24.97 \pm 9.96$ & $36.44 \pm 10.59$ \\
\hline Male & 84 & $22.89 \pm 10.86$ & $61.41 \pm 14.94$ & $-25.59 \pm 9.68$ & $39.42 \pm 11.70$ \\
\hline Female & 128 & $20.42 \pm 12.73$ & $65.02 \pm 15.48$ & & $45.68 \pm 12.60$ \\
\hline Age in yrs & & & & $-35.81 \pm 8.39$ & $42.43 \pm 11.52$ \\
\hline $20-29$ & 36 & $17.95 \pm 17.46$ & $81.49 \pm 14.27$ & $-29.92 \pm 9.33$ & $37.61 \pm 12.50$ \\
\hline $30-39$ & 28 & $21.39 \pm 13.66$ & $72.36 \pm 15.80$ & $-26.65 \pm 8.69$ & $34.90 \pm 9.14$ \\
\hline $40-49$ & 36 & $21.08 \pm 11.46$ & $64.26 \pm 14.29$ & $-24.11 \pm 7.00$ & $31.96 \pm 7.71$ \\
\hline $50-59$ & 52 & $18.93 \pm 10.37$ & $59.01 \pm 9.83$ & $-19.45 \pm 10.21$ & $38.71 \pm 9.07$ \\
\hline $60-69$ & 32 & $23.42 \pm 8.76$ & $51.41 \pm 10.05$ & $-14.66 \pm 9.6$ & \\
\hline $70-79$ & 28 & $28.56 \pm 7.48$ & $53.37 \pm 12.86$ & & \\
\hline
\end{tabular}

\section{Results}

We divided the 212 asymptomatic volunteers into 2 sex groups (female subjects [n $=128]$ and male subjects $[\mathrm{n}=$ 84]) and into 6 age groups, using 10-year intervals (20-29 years $[\mathrm{n}=36], 30-39$ years $[\mathrm{n}=28], 40-49$ years $[\mathrm{n}=36]$, 50-59 years $[\mathrm{n}=52], 60-69$ years $[\mathrm{n}=32]$, and $70-79$ years $[\mathrm{n}=28])($ Table 1$)$.

Based on the degree of cervical disc degeneration, C2-3 findings were divided into 2 groups (no degeneration [ $\mathrm{n}=$ $168]$ and mild degeneration [ $n=44]$ ); $C 3-4$ and C4 -5 findings were divided into 3 groups (no degeneration $[\mathrm{n}=116$ and $n=80$, respectively], mild degeneration $[n=84$ and $n=$ 104, respectively], and moderate degeneration [ $\mathrm{n}=12$ and $\mathrm{n}$ $=28$, respectively]); C5-6 and C6-7 findings were divided into 4 groups (no degeneration $[\mathrm{n}=72$ and $\mathrm{n}=80$, respectively], mild degeneration [ $\mathrm{n}=56$ and $\mathrm{n}=64$, respectively], moderate degeneration [ $\mathrm{n}=52$ and $\mathrm{n}=44$, respectively], and severe degeneration [ $\mathrm{n}=32$ and $\mathrm{n}=24$, respectively]) (Table 2).

C2-7 alignment was $21.40^{\circ} \pm 12.15^{\circ}$, total ROM was $63.59^{\circ} \pm 15.37^{\circ}$, flexion $\mathrm{ROM}$ was $-25.34^{\circ} \pm 9.80^{\circ}$, and extension ROM was $38.24^{\circ} \pm 11.31^{\circ}$ (Table 1). This measurement showed excellent intrarater agreement (ICC range 0.87-0.97) and excellent interrater agreement (ICC range 0.83-0.94).

Sex was significantly associated with cervical alignment, total ROM, and segmental ROM at 2 of the levels assessed (C2-3 and C5-6) ( $\mathrm{p}<0.05)$. Age was significantly associated with total ROM (Fig. 2, Tables 3 and 4) and segmental ROM at all levels $(\mathrm{p}<0.05)$ (Fig. 3, Tables 3 and 4). Cervical disc degeneration at the level of interest was significantly associated with C4-5, C5-6, and C6-7

TABLE 2. Severity of disc degeneration by level*

\begin{tabular}{lccccc}
\hline Degeneration & C2-3 & C3-4 & C4-5 & C5-6 & C6-7 \\
\hline None & 168 & 116 & 80 & 72 & 80 \\
\hline Mild & 44 & 84 & 104 & 56 & 64 \\
\hline Moderate & - & 12 & 28 & 52 & 44 \\
\hline Severe & - & - & - & 32 & 24 \\
\hline
\end{tabular}

${ }^{*}$ Values represent numbers of subjects.
ROM ( $\mathrm{p}<0.05$ ) (Fig. 4, Tables 3 and 4). Cervical disc degeneration at the adjacent levels (above and below) and the related 3 variables (height loss, anterior osteophytes, and endplate sclerosis) of the 3 levels showed no significant association with cervical segmental ROM ( $\mathrm{p}>0.05)$.

Cervical alignment had no significant association with total ROM ( $p>0.05)$, but had a significant negative association with flexion ROM ( $\mathrm{p}<0.05)$ and a significant positive association with extension ROM $(\mathrm{p}<0.05)$.

\section{Discussion}

This study aimed to establish standard parameters for alignment and range of motion of the cervical spine and to identify factors that influence these variables.

Our data indicate that sex is an influential factor for cervical alignment, with a regression coefficient of -2.47 , showing that cervical alignment in female subjects was $2.47^{\circ}$ less than that in male subjects. Cervical alignment showed no significant difference between successive age groups, but there was a trend toward increased alignment

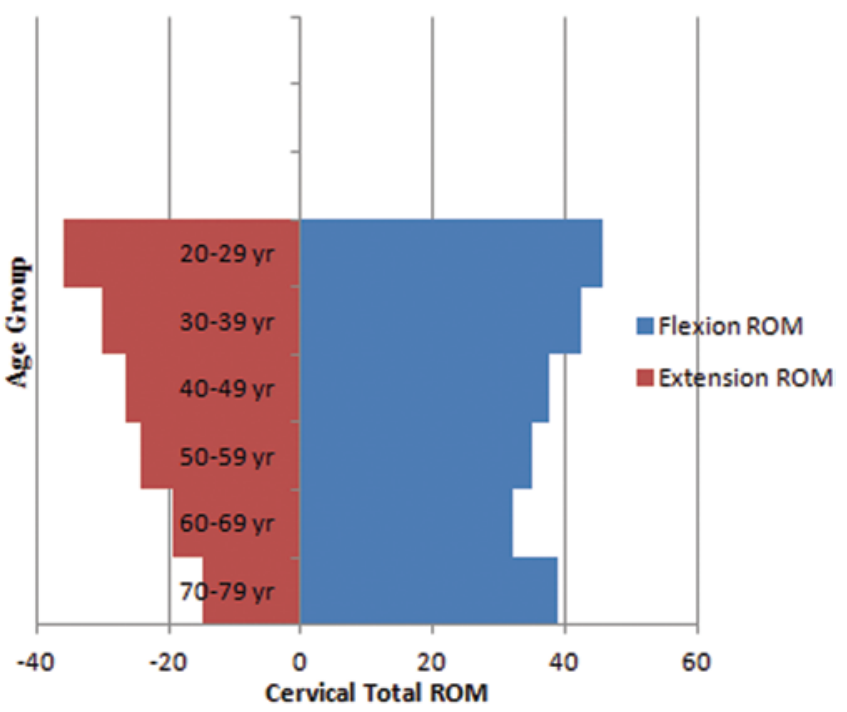

FIG. 2. Bar graph showing cervical total ROM in each age group. The $x$-axis indicates ROM in degrees. Figure is available in color online only. 
TABLE 3. Cervical segmental ROM stratified by sex, age, and severity of disc degeneration

\begin{tabular}{lcccccc}
\hline & & \multicolumn{5}{c}{ Mean \pm SD $\left(^{\circ}\right)$} \\
\cline { 3 - 6 } Group & No. of Subjects & C2-3 & C3-4 & C4-5 & C5-6 & C6-7 \\
\hline Total & 212 & $9.46 \pm 4.04$ & $13.66 \pm 4.52$ & $15.79 \pm 4.15$ & $14.15 \pm 6.14$ & $12.47 \pm 5.86$ \\
\hline Sex & & & & & $9.72 \pm 4.28$ \\
\hline Male & 84 & $7.73 \pm 3.42$ & $11.97 \pm 3.41$ & $14.08 \pm 3.24$ & $11.04 \pm 4.82$ & $14.28 \pm 6.11$ \\
\hline Female & 128 & $10.59 \pm 4.07$ & $14.77 \pm 4.86$ & $16.90 \pm 4.34$ & $16.19 \pm 6.11$ & \\
\hline Age in yrs & & & & & & $20.68 \pm 3.43$ \\
\hline $20-29$ & 36 & $13.67 \pm 3.92$ & $18.07 \pm 5.15$ & $20.38 \pm 4.25$ & $21.27 \pm 4.45$ & $16.23 \pm 4.90$ \\
\hline $30-39$ & 28 & $9.84 \pm 5.28$ & $16.14 \pm 5.10$ & $17.69 \pm 3.42$ & $15.39 \pm 3.54$ & $10.48 \pm 3.30$ \\
\hline $40-49$ & 36 & $8.34 \pm 2.96$ & $12.73 \pm 3.45$ & $14.80 \pm 3.10$ & $13.44 \pm 3.54$ & $10.11 \pm 4.51$ \\
\hline $50-59$ & 52 & $9.51 \pm 2.82$ & $13.09 \pm 3.59$ & $14.42 \pm 3.89$ & $13.01 \pm 4.64$ & $9.42 \pm 4.10$ \\
\hline $60-69$ & 32 & $7.14 \pm 2.98$ & $11.08 \pm 2.36$ & $13.88 \pm 2.74$ & $11.05 \pm 3.27$ & $8.59 \pm 4.20$ \\
\hline $70-79$ & 28 & $7.67 \pm 3.99$ & $10.73 \pm 1.97$ & $13.92 \pm 3.36$ & $10.34 \pm 6.70$ & $16.71 \pm 5.90$ \\
\hline Degeneration & & & & & & $11.89 \pm 2.08$ \\
\hline None & & $9.57 \pm 3.92$ & $14.03 \pm 4.73$ & $18.18 \pm 3.96$ & $19.53 \pm 5.91$ & $8.54 \pm 4.29$ \\
\hline Mild & & $9.05 \pm 4.68$ & $13.58 \pm 3.77$ & $14.83 \pm 3.72$ & $13.59 \pm 4.07$ & $7.07 \pm 5.77$ \\
\hline Moderate & & - & $10.69 \pm 2.14$ & $12.44 \pm 2.39$ & $10.83 \pm 3.75$ & $8.43 \pm 2.66$ \\
\hline Severe & & - & - & - & &
\end{tabular}

values with age (increasing from $17.95^{\circ} \pm 17.46^{\circ}$ in the $3 \mathrm{rd}$ decade to $28.56^{\circ} \pm 7.48^{\circ}$ in the 8 th decade).

Both sex and age influenced total ROM, with a regression coefficient for sex of 3.86, showing that the total ROM in female subjects was $3.86^{\circ}$ larger than that in male subjects. The regression coefficient of age was -6.46 , showing that the total ROM decreased $6.46^{\circ}$ for each decade of aging. The total ROM was $81.49^{\circ} \pm 14.27^{\circ}$ in the 3rd decade and decreased to $53.37^{\circ} \pm 12.86^{\circ}$ in the 8 th decade. Flexion ROM decreased to a greater extent than did the extension ROM.

Sex influenced C2-3 and C5-6 ROM, and age influenced segmental ROM at all 5 disc levels. The severity of disc degeneration at the level of interest influenced C4-5, C5-6, and C6-7 ROM. The regression coefficient of sex was 2.11 at C2-3 and 2.48 at C5-6, showing that segmental ROM in female subjects was $2.11^{\circ}(\mathrm{C} 2-3)$ and $2.48^{\circ}$ (C5-6) larger than in male subjects. The average regression coefficient of age was -1.28 (range -0.94 to -1.75 ), indicating that segmental ROM decreased $1.28^{\circ}$ for each decade of aging. The average regression coefficient of the severity of disc degeneration at the level of interest (C4-5,
C5-6, and C6-7) was -2.26 (range -1.96 to -2.63 ), showing that segmental ROM decreased $2.26^{\circ}$ for each category increase in disc degeneration at the level of interest. We also found that C5-6 had the largest segmental ROM in subjects in the 3rd decade, while C4-5 had the largest in those in the 8th decade.

Cervical alignment had no significant association with total ROM, but it had a significant negative association with flexion ROM and a significant positive association with extension ROM. The regression coefficient of flexion ROM was -0.44 , showing that $0.44^{\circ}$ of flexion ROM was lost with each degree increase in alignment. The regression coefficient of extension ROM was 0.46 , indicating that an increase of $0.46^{\circ}$ of extension ROM occurred for each degree increase in alignment.

There are several limitations in this study. First, measurement errors are possible; to minimize them, the plain radiographs were measured by 3 spine surgeons (blinded to previous measurements or any identifying information) 3 times each, and the reliability of the measurement was represented by the ICC. Additionally, flexion and extension radiographs of each volunteer's cervical spine were

TABLE 4. Summary of factors found to have a significant influence on total and segmental ROM through linear regression analysis

\begin{tabular}{lcccc}
\hline \multicolumn{1}{c}{ ROM } & Disc Degeneration & Age & Sex & Constant \\
\hline Total $(\mathrm{C} 2-7)$ & NA & $-6.463(p<0.001) \dagger$ & $3.863(p=0.035)^{*}$ & 92.095 \\
\hline C2-3 & - & $-0.942(p=0.004) \dagger$ & $2.114(p=0.045)^{*}$ & 11.224 \\
\hline C3-4 & - & $-1.393(p<0.001) \dagger$ & - & 21.285 \\
\hline C4-5 & $-1.960(p=0.016)^{*}$ & $-0.949(p=0.005) \dagger$ & - & 22.454 \\
\hline C5-6 & $-2.630(p<0.001) \dagger$ & $-1.367(p=0.001) \dagger$ & $2.476(p=0.037)^{*}$ & 20.839 \\
\hline C6-7 & $-2.187(p=0.001) \dagger$ & $-1.754(p<0.001) \dagger$ & - & 24.378 \\
\hline NA $=$ not applicable. & & & & \\
${ }^{*} p<0.05$. & & & & \\
$\dagger p<0.01$. & & &
\end{tabular}




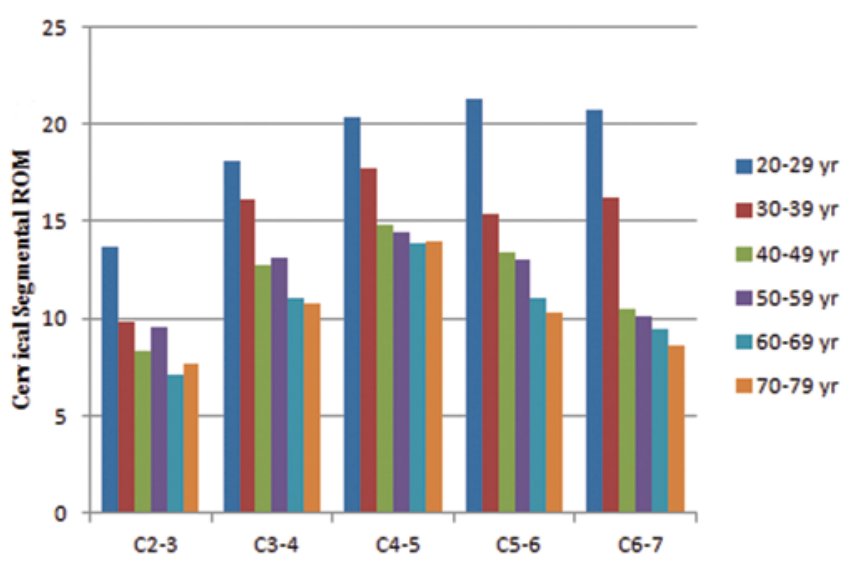

FIG. 3. Bar graph showing cervical segmental ROM in each age group. The $y$-axis indicates ROM in degrees. Figure is available in color online only.

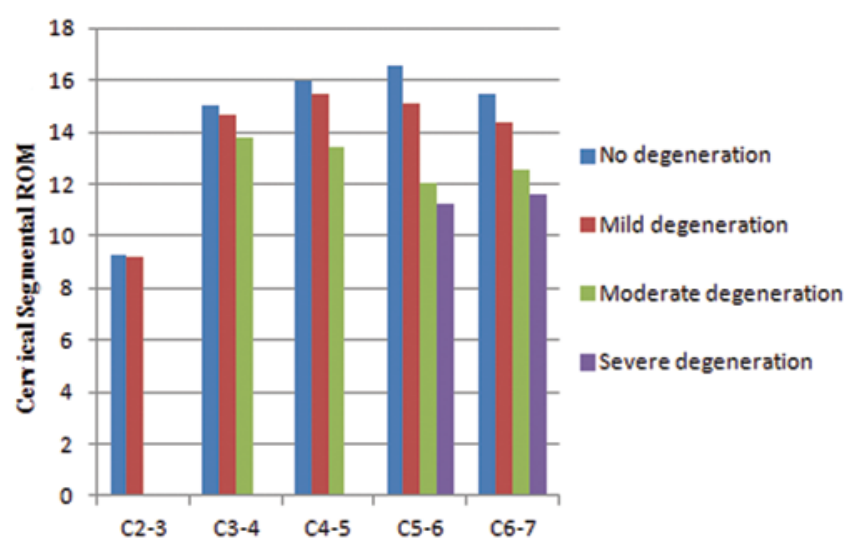

FIG. 4. Bar graph showing cervical segmental ROM for each severity category of disc degeneration. The $y$-axis indicates ROM in degrees. Figure is available in color online only.

superimposed using Mimics software to reduce the steps in the manual measurement. Second, not all patients' C2-7 levels could be placed into one of the 4 cervical disc degeneration severity groups. Severe disc degeneration is uncommon at cervical levels other than C4-7, especially in asymptomatic individuals.

\section{Conclusions}

The standard parameters and factors identified in our study should be useful for the clinical diagnosis and biomechanical study of cervical degenerative diseases and cervical instability, and should also be of value for the design and application of cervical disc arthroplasty tailored to the individual patient.

\section{References}

1. Bible JE, Simpson AK, Emerson JW, Biswas D, Grauer JN: Quantifying the effects of degeneration and other patient factors on lumbar segmental range of motion using multivariate analysis. Spine (Phila Pa 1976) 33:1793-1799, 2008

2. Coric D, Nunley PD, Guyer RD, Musante D, Carmody
$\mathrm{CN}$, Gordon CR, et al: Prospective, randomized, multicenter study of cervical arthroplasty: 269 patients from the Kineflex|C artificial disc investigational device exemption study with a minimum 2-year follow-up. Clinical article. J Neurosurg Spine 15:348-358, 2011

3. Côté P, Cassidy JD, Yong-Hing K, Sibley J, Loewy J: Apophysial joint degeneration, disc degeneration, and sagittal curve of the cervical spine. Can they be measured reliably on radiographs? Spine (Phila Pa 1976) 22:859-864, 1997

4. Dvorak J, Froehlich D, Penning L, Baumgartner H, Panjabi MM: Functional radiographic diagnosis of the cervical spine: flexion/extension. Spine (Phila Pa 1976) 13:748-755, 1988

5. Gelb DE, Lenke LG, Bridwell KH, Blanke K, McEnery KW: An analysis of sagittal spinal alignment in 100 asymptomatic middle and older aged volunteers. Spine (Phila Pa 1976) 20:1351-1358, 1995

6. Grauer JN, Panjabi MM, Cholewicki J, Nibu K, Dvorak $\mathrm{J}$ : Whiplash produces an S-shaped curvature of the neck with hyperextension at lower levels. Spine (Phila Pa 1976) 22:2489-2494, 1997

7. Grob D, Frauenfelder H, Mannion AF: The association between cervical spine curvature and neck pain. Eur Spine J 16:669-678, 2007

8. Guigui P, Benoist M, Deburge A: Spinal deformity and instability after multilevel cervical laminectomy for spondylotic myelopathy. Spine (Phila Pa 1976) 23:440-447, 1998

9. Harrison DE, Harrison DD, Cailliet R, Troyanovich SJ, Janik TJ, Holland B: Cobb method or Harrison posterior tangent method: which to choose for lateral cervical radiographic analysis. Spine (Phila Pa 1976) 25:2072-2078, 2000

10. Jackson BL, Harrison DD, Robertson GA, Barker WF: Chiropractic biophysics lateral cervical film analysis reliability. J Manipulative Physiol Ther 16:384-391, 1993

11. Kettler A, Rohlmann F, Ring C, Mack C, Wilke HJ: Do early stages of lumbar intervertebral disc degeneration really cause instability? Evaluation of an in vitro database. Eur Spine J 20:578-584, 2011

12. Lee H, Nicholson LL, Adams RD: Cervical range of motion associations with subclinical neck pain. Spine (Phila Pa 1976) 29:33-40, 2004

13. Lewis G: Nucleus pulposus replacement and regeneration/ repair technologies: present status and future prospects. J Biomed Mater Res B Appl Biomater 100:1702-1720, 2012

14. Liu B, Liu Z, VanHoof T, Kalala J, Zeng Z, Lin X: Kinematic study of the relation between the instantaneous center of rotation and degenerative changes in the cervical intervertebral disc. Eur Spine J 23:2307-2313, 2014

15. Machino M, Yukawa Y, Hida T, Ito K, Nakashima H, Kanbara S, et al: Cervical alignment and range of motion after laminoplasty: radiographical data from more than 500 cases with cervical spondylotic myelopathy and a review of the literature. Spine (Phila Pa 1976) 37:E1243-E1250, 2012

16. Miyazaki M, Hymanson HJ, Morishita Y, He W, Zhang H, Wu G, et al: Kinematic analysis of the relationship between sagittal alignment and disc degeneration in the cervical spine. Spine (Phila Pa 1976) 33:E870-E876, 2008

17. Ohara A, Miyamoto K, Naganawa T, Matsumoto K, Shimizu $\mathrm{K}$ : Reliabilities of and correlations among five standard methods of assessing the sagittal alignment of the cervical spine. Spine (Phila Pa 1976) 31:2585-2592, 2006

18. Okada E, Matsumoto M, Ichihara D, Chiba K, Toyama Y, Fujiwara H, et al: Aging of the cervical spine in healthy volunteers: a 10-year longitudinal magnetic resonance imaging study. Spine (Phila Pa 1976) 34:706-712, 2009

19. Okada E, Matsumoto M, Ichihara D, Chiba K, Toyama Y, Fujiwara H, et al: Does the sagittal alignment of the cervical spine have an impact on disk degeneration? Minimum 10-year follow-up of asymptomatic volunteers. Eur Spine J 18:1644-1651, 2009 
20. Penning L: Normal movements of the cervical spine. AJR Am J Roentgenol 130:317-326, 1978

21. Satomi K, Nishu Y, Kohno T, Hirabayashi K: Long-term follow-up studies of open-door expansive laminoplasty for cervical stenotic myelopathy. Spine (Phila Pa 1976) 19:507510, 1994

22. Simpson AK, Biswas D, Emerson JW, Lawrence BD, Grauer JN: Quantifying the effects of age, gender, degeneration, and adjacent level degeneration on cervical spine range of motion using multivariate analyses. Spine (Phila Pa 1976) 33:183186,2008

23. Tian W, Han X, Li ZY, Mao JP, Sun YQ, James Albert T: Reversal of anterior cervical discectomy and fusion with cervical artificial disc replacement: regain motion after 9 years fusion. J Spinal Disord Tech 26:55-59, 2013

24. Walraevens J, Demaerel P, Suetens P, Van Calenbergh F, van Loon J, Vander Sloten J, et al: Longitudinal prospective longterm radiographic follow-up after treatment of single-level cervical disk disease with the Bryan Cervical Disc. Neurosurgery 67:679-687, 2010

25. Walraevens J, Liu B, Meersschaert J, Demaerel P, Delye H, Depreitere B, et al: Qualitative and quantitative assessment of degeneration of cervical intervertebral discs and facet joints. Eur Spine J 18:358-369, 2009

26. Yukawa Y, Kato F, Suda K, Yamagata M, Ueta T: Age-related changes in osseous anatomy, alignment, and range of motion of the cervical spine. Part I: Radiographic data from over 1,200 asymptomatic subjects. Eur Spine J 21:1492-1498, 2012

\section{Author Contributions}

Conception and design: B Liu. Acquisition of data: Z Liu, Zeng. Analysis and interpretation of data: B Liu, Wu, Z Liu. Drafting the article: Wu. Critically revising the article: B Liu, Okito. Reviewed submitted version of manuscript: Van Hoof, Okito. Statistical analysis: Wu, Zeng. Administrative/technical/material support: Van Hoof.

\section{Correspondence}

Baoge Liu, Tiantan Xili No. 6, Dongcheng District, Beijing 100050, China. email: baogeliu@hotmail.com. 